JWAM

13,1

6

Received 1 November 2020 Revised 11 December 2020 Accepted 1 January 2021

\section{Self-managed and work-based learning: problematising the workplace-classroom skills gap}

\author{
Iro Konstantinou and Elizabeth Miller \\ Pearson College London, London, UK
}

\begin{abstract}
Purpose - The authors explore the ways work-based learning (WBL) can help degree apprentices cross the gaps between the workplace and the classroom, arguing that problem-based learning allows them to become aware of the overlaps in skills required to succeed between the two sites of learning.

Design/methodology/approach - This case study of a self-managed learning module uses a workshop methodology to understand the ways 61 undergraduate business management apprentices in the UK navigate the boundaries between work and learning and develop skills across both domains.

Findings - The authors' findings suggest that degree apprentices do not always perceive the two sites as overlapping in terms of what skills are required and how learning takes place. However, WBL modules have the potential to make them aware of how one informs and reinforces the other. Students identified teamwork, communication and reflection as necessary at the workplace and in their studies. They also viewed learning agility at critical, especially in the time of coronavirus disease 2019 .

Originality/value - The paper adds to the existing literature exploring how WBL learning can help minimise the gap between the classroom and the workplace by adding the analysis of the case study. Those interested in developing modules which embed theory and practice can benefit from the discussion on how such modules enable students to reflect on the crossover between the two sites, not only on degree apprenticeships but higher education degrees broadly.
\end{abstract}

Keywords Work-based learning, Problem-based learning, Higher education, Skills development, Skills gap, Degree apprenticeship

Paper type Research paper

\section{Introduction}

The skills gap between higher education graduates and employer needs has been explored widely. Livanos (2010) describes the situation in Greece; Mok (2016) in China; Joshua et al. (2015) in Nigeria; Graham et al. (2019) in South Africa; Moore and Morton (2017) in Australia to name just a few examples. In the United Kingdom (UK), this has been a concern of universities, the government and employers alike for several years. In 2015, the funding model of state-funded universities in the UK changed and placed a renewed emphasis on results and employment outcomes, increasing the pressures on universities to offer value for money for students (BIS 2016). As part of such a drive, many institutions are looking to embed employability training into their courses to ensure tangible results when students graduate (Bates et al., 2018). Despite the drive for higher education institutions (HEIs) to provide skills for the workplace, there is little consideration of how to do this successfully, resulting in a divergence between what happens in the workplace and what students do in higher education. This paper provides a UK-based case study of how work-based learning

(C) Iro Konstantinou and Elizabeth Miller. Published in Journal of Work-Applied Management. Published by Emerald Publishing Limited. This article is published under the Creative Commons Attribution (CC BY 4.0) licence. Anyone may reproduce, distribute, translate and create derivative works of this article (for both commercial and non-commercial purposes), subject to full attribution to the original publication and authors. The full terms of this licence may be seen at http://creativecommons.org/licences/by/4.0/ legalcode 
(WBL) and, a problem-based learning (PBL) approach, can help students cross the boundaries between their workplace and classroom learning. We also show that in doing so, they deploy and articulate the employability skills that will become part of their professional identity. In this paper, we have taken a PBL approach to WBL, where we situate learning as occurring in the relational space between work and formal education contexts (Ramsey, 2011).

WBL models are diverse. While they can involve simulations and one-off industry projects, the case study presented here focusses on a WBL programme where the students' professional practice is tightly linked to the curriculum (Boud et al., 2020) because these students are degree apprentices (DAs). In 2015, the British government announced the introduction of degree apprenticeships to meet employer demand for skills as part of the government's "long-term economic plan" (Department for Business, Innovation \& Skills BIS and Prime Minister's Office, 2015). This case study involves students on a Chartered Manager Degree Apprenticeship. These students study their BA, Business Management, at our institution, a private, HEI in central London. The links between work and study are integral to degree apprenticeships, and as part of their degree at our institution, we require them to undertake a PBL module called "Self-Managed Learning" (SML). In their SML modules, the DAs must work with their managers and wider teams to identify a problem or opportunity in their workplace and then through research, find and evaluate potential solutions. Alongside this, we ask them to reflect on the skills they have developed in their work and academic lives.

By virtue of their job roles, which must all be professional roles carefully reviewed to ensure they are in line with the knowledge, skills and behaviours that form the Chartered Manager (Degree) apprenticeship standard, our students are both management learners, in that this is their field of study, and "manager-learners" (Ramsey, 2014), as junior managers, who relate their learning to their workplace, and vice versa. Ramsey's "scholarship of practice" (2014) suggests that the relations between ideas and action are critical, and that teaching should emphasise this relationship and not just academic theory. This approach became critical as this research was conducted in the summer of 2020 when the coronavirus disease 2019 (COVID-19) pandemic was having a significant impact on individuals, society and the economy. The disruption caused by COVID-19 highlighted the importance of particular skills in the workplace - notably agility, communication, problem-solving and teamwork - as a way of navigating rapid change. The experiential approach we outline below highlights how WBL can address the skills gap by encouraging students to think about the multiple crossings between the classroom and their workplace.

\section{Literature review}

The skills gap: which skills are needed and who should teach them?

As Andrews and Higson (2008) outline, European universities are increasingly required to produce highly mobile graduates able to respond to the ever-changing needs of the contemporary workplace, especially with the recent expansion of higher education provision. Scholars debate whether employability should be the focus of HEIs (Mccowan, 2015) and if this is the case, which skills should be the focus. Bridgstock (2009), for example, argues that HEIs should equip graduates with self-management skills to be able to navigate their careers, while Fajaryati and Akhyar (2020) argues for skills needed in the age of innovation and technology such as communication, teamwork, problem-solving and technological skills. However, employers are still expressing concerns about whether graduate labour can meet their needs (CBI and Pearson, 2018). Despite the increasing attempts by universities to increase employability skills in students, students do not always see the benefit in such attempts with a perceived limited alignment between what students feel they need and what universities offer (Tymon, 2013). There are differences in what students perceive as essential skills and what academics see as important (Hodge and Lear, 2011), while another area of
Self-managed and workbased learning 
JWAM

13,1 concern is that often graduates do not place as much importance on soft skills as employers do (Succi and Canovi, 2020).

\section{Crossing the distance between the classroom and the workplace}

The convergence of the workplace and classroom through workplace learning programmes is driven in the UK by education policy reforms seeking to redress the skills gap (Bravenboer, 2018). This convergence creates opportunities to "bridge" (Bates and Sampford, 2005; Svensson and Randle, 2005) the gap between formal learning in educational settings and the often informal learning that occurs in the workplace. As Choy (2018) argues, workplace learning is "ubiquitous" and integrating this with a formal curriculum for learning in an educational institution allows for meaningful learning that adds value to both the learner and their employer (Billett, 2001). Minimising this gap benefits students through increased confidence, social and employability skills, and improvements in academic performance (Bates and Sampford, 2005).

For students on explicitly work-integrated learning programmes, reflecting on professional and classroom learning experiences can help them engage in "deep learning" and convert "hands-on" experiential learning to abstract conceptualisation (Young, 2018). However, others argue we should start by challenging the "unhelpful" conception of theory and practice as being separate (Bravenboer and Lester, 2016) in the first place. The overlap in sites of learning for students on work-integrated learning programmes is a topic that deserves further research. Post-structural approaches "problematise the imagined geographies of learning as distinct fields of the "workplace" versus "educational institution"” (Bound et al., 2018, p. 245). Instead, a relational approach is a useful way of reconceptualising the "bridge" between the classroom and the workplace, which frames learning as occurring inside and across these spaces (Bound et al., 2018). Practices at different sites of learning and the relationships between them become a new "site" of learning (Nicolini, 2011). However, our experience of students on WBL programmes is that they see their work and learning as occurring on separate, albeit linked, sites. An aim of the project forming our case study, therefore, is helping students see the relationships between sites through summative assessment requiring learners to explicitly reflect on skills developed across and between sites while solving a "real-world" problem. We argue that the metaphor of a bridge between work and HEIs is helpful, but this bridge is more helpfully understood as a series of relational "crossings" between sites of learning.

\section{PBL and the development of skills and competencies: self-managed learning}

$\mathrm{PBL}$ is an experiential learning method that contextualises academic learning in a way that scholars argue can minimise the perceived distance between the worlds of work and education (Scholtz, 2020; Smith et al., 2007). PBL not only develops skills and competencies in university students, it allows them to formally display these skills (Heaviside et al., 2018), something that may not always occur in the workplace where informal demonstrations of skills are essential. In management education, research has shown that the interactions with tutors and those at the workplace are both crucial in developing transferable skills in PBL (Carvalho, 2016). Giving students the chance to develop, reflect on and showcase the competencies and skills they develop is seen by the students themselves as important. Students do not all experience learning in the same way (Cunliffe, 2002) and yet research has found that even when students disliked PBL, they could still see its effectiveness in developing employability skills (Smith et al., 2013). Perhaps critical to PBL is the sense of autonomy students develop and the self-management or regulation developed through PBL. Self-management is linked to strong employment outcomes for graduates. Jackson and Wilton argue it is a way for students to understand "gaps" they must cross to master 
professional skills and competencies (Jackson and Wilton, 2016) and the character traits (Wellman, 2010) that will aid their crossing.

\section{The importance of incidental learning in WBL}

WBL also has the potential for what Knowles (1970) describes as incidental learning: the ability to learn from others, who tend to be experts, but also to practically apply some of the things one learns through formal learning. Le Clus (2011) makes a similar point by noting that learning takes place not just through formal structures which organisations put in place but very often through learning embedded in everyday activities. Le Clus suggests that learning and working are synonymous since it is not possible to work without learning new things. Billett (1996) has talked about the workplace as a site for learning where skills and knowledge can be acquired daily and where theory and practice converge in a way which is beneficial for the employees. Junior and more senior employees alike have areas of "knowledgeable skills" that they can share with others in their workplace (Fuller et al., 2005). Boud and Garrick (1999) have described informal interaction with work colleagues as a predominant way of learning in the workplace since learning can often happen through unplanned conversations and chance encounters. Empirical work on coaching training by Crisp (2018) supports this point and points to the importance of learning to be done on an informal basis with encouragement and support from experts.

\section{Methodology}

Designing a project-based, skills development module

Before outlining our approach to data collection, we discuss our approach to experiential, problem-based modules to enable the convergence of learning between the workplace and the classroom, through our WBL modules. By taking an experiential approach which integrates reflection and problem-solving, we have updated one of our WBL modules to ensure better integration across the two spheres of learning. SML modules require students to solve a real work-based problem which can be decided in consultation with their managers or, especially at a higher level, through the students' ability to identify problems at their workplace. Our role as tutors is to help them contextualise this work (Dahlgren, 2000) and facilitate classroom environments where they can develop the confidence to articulate the skills they acquire.

Starting with a problem they have identified in the workplace students conduct a literature review which focusses on what solutions can be found in academic literature but also in industry publications, such as case studies of best practice. After completing the literature review and having identified several viable solutions, we ask students to evaluate whether these solutions would be applicable in their context. By taking into consideration different parameters and variables, they narrow down the scope of what can work in their contexts. For this process, they are encouraged to engage with varying models of good practice; seek feedback from colleagues and classroom peers; reflect on their relationship with stakeholders; and identify risks and mitigation strategies. The report they produce for summative assessment concludes with a set of recommendations, which at final year undergraduate (L6) can be sophisticated and form the basis of a framework of their own.

As part of the assessment, students must also reflect on the skills they have developed through the module. In redesigning the module, we drew from the literature which looks at which skills are important for graduates to be employable while also succeed academically. Thus the skills that we ask them to reflect on are those applicable to all degree students, not just apprentices. There is some crossover in the skills laid out in the apprenticeship standard, such as communication and working with others, but our approach is broader and less focussed on business management specific skills. Our purpose is to give as many
Self-managed and workbased learning

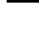


JWAM

13,1

opportunities for students to become independent learners while they are also learning from each other. Most of the seminars are spent on students discussing their projects in groups, giving feedback and suggesting new areas to develop for each other's projects. In the workplace, students are encouraged to gather feedback from colleagues and discuss their work regularly with those in their teams. We are careful not to assume that critical (Wall, 2016) boundary between the workplace and the degree through PBL. Below we outline how the students understand this process and provide examples of how they believe the two learning spheres can be brought together through this problem-solving experiential learning approach.

\section{Workshops as a means of data collection}

Ørngreen and Levinsen (2017) outline the potential of workshops for data collection, distinguishing between workshops to achieve a goal; as practice with specific outcomes and as research methodology. In all cases, they reviewed workshops that were conducted by someone with expertise in an area who encourages active participation (Ørngreen and Levinsen (2017)). The benefit for the organiser is that they can get an insight into what participants think. The benefits for the participants are that the main outcome of a workshop is that it produces a concrete product, such as generating new insights, learning from others, suggestions and so on. Moreover, even though workshops very often have predefined activities but not always a predetermined outcome. For Ahmed and Asraf (2018, p. 1508) for workshops to be successful, they need to have activities that provide a scope for the participants to interact and learn collaboratively. The facilitator must create an environment where participants feel that their voices are important; the activities of the workshop must be relevant to the main objective of the workshop; ethical considerations must be taken into account, e.g. having the participants sign the informed consent form before the workshop. Our workshop was based on our understanding of our students as having knowledge developed between the workplace and classroom and understanding that the sharing of this knowledge amongst students is a valuable way for them to learn (Fuller et al., 2005).

For our data collection, we used two groups of L6 students $(n=61)$ in one of their 2-h weekly seminars. During the seminar, the participants were asked to (1) define the skills which are given as part of the module's skills development framework (problem-solving; teamwork and communication; employability; planning and organisation; self-reflection; analytical skills and critical thinking; leadership)and identify their potential importance for their workplace and classroom; (2) provide concrete evidence of how these skills have been or can be developed both at the workplace and the classroom (drawing from previous terms if necessary); (3) consider overlaps between the workplace and the classroom and how the two can inform each other. Each group had around 30 students and they were split into six groups (12 in total). The tutor had created templates of the activities on Google slides where students were asked to take notes as they discussed in their groups in the "breakout rooms". The tutor did not participate in the group discussions in these breakout rooms but was monitoring discussion through the notes they students were taking on the shared slides and by giving prompts and feedback on the slides.

\section{The challenges of conducting research online}

Even though the discussion in the breakout groups was more natural with everyone having their microphones on, when the participants were brought back to the "main room" most of them were writing in the chatbox while the tutor was on the microphone. Moreover, the students did not have their cameras on and as such the tutor could not see their reactions or 
facial expressions. The challenges around building rapport with participants in online research have been widely discussed (e.g. O'Connor et al., 2008) and we found that some of these of these challenges were prevalent in our research. The tutor had met some of the students face to face in previous terms but not all of them. Holding a workshop online made it challenging to monitor conversations as much as we would have liked and posed challenges around ensuring that everyone in the group participated and stayed motivated. It also meant that any nonverbal cues, which can provide richer data, were not possible to obtain (Ochieng et al., 2018). If it had not been for COVID-19 and the restrictions it posed on face-to-face meetings, then this workshop would be face to face and allowed us to gain an insight into the reactions of the participants and ensure everyone participated and benefitted from this. However, perhaps giving the space to students to discuss amongst themselves can also be a powerful way to collect richer data. Moreover, the online format of this meant that a much larger group can come together, something which would not have worked that easily in a seminar room.

\section{Data analysis}

The workshop objectives, as outlined above, guided us in our analysis of the data. By taking the three main objectives, we structured our analysis accordingly and included some representative responses in our findings below. The evidence provided by students was chosen based on their willingness to share their work. Based on our experience in teaching the module we believe that they offer a good representation of the students' work.

Even though our sample size $(n=61)$ is not large enough to make any generalisations, we believe that it can provide the basis for further discussion and research around how WBL modules can bridge the gap between the learning taking place in the workplace and the classroom, both formal and informal.

\section{Ethical considerations}

Before commencing the term, we informed students through an email that we will be collecting confidential data during the term in our attempts to revise the modules in a way which can benefit students. The email explained what the purpose of our research was for and that students could withdraw their consent at any time during the term. For the purposes of this paper, we sought verbal consent from students at the beginning of the workshop and explained to them that if they did not want their responses to be recorded, they did not have to put comments on the slides. This way they would still participate in the discussion but not express any of their views in writing which was used as data. Since all the responses on the slides were anonymous, we cannot be sure which students chose to not record their responses. The seminars are usually recorded but the breakout rooms are not, and we only used the data given on the shared Google Slides and none of the comments in the whole class debriefs when the recording was on. This way we ring-fenced some time where participants could speak more freely or ask questions. We asked specifically for some concrete evidence to be shared with us and this was done on a voluntary basis by students, via email. These examples draw from students' previous assessments and since these have been marked and the grades have been confirmed we were confident that the students did not feel their marks were at stake.

\section{Findings}

The findings below demonstrate the potential of problem-based, experiential modules in degree apprenticeships to bridge the learning spheres of the classroom and the workplace. Our students spend four days a week in the workplace and one in the classroom and do not 
JWAM

13,1

readily collapse what they see as the rigid boundaries between each setting. Following the objectives, we set out for the workshop we provide examples of skills students view as important and what they mean to them; evidence of how students think they develop these skills both at the workplace and the classroom; outline overlaps between the two sites of learning.

\section{Identifying skills needed at the workplace and the classroom}

The first part of the workshop asked students to identify which skills from the framework we provide them they believe are needed both the workplace and their academic studies. Overwhelmingly, students pointed to self-reflection and teamwork, although other skills were mentioned as important. It is vital to note that they did not consider any of the skills in the framework as not relevant. As outlined in the literature review, $\mathrm{PBL}$ has the potential to equip students with several skills which can be easily transferable across sites and beyond their studies. Here are some examples of how the students reflected on the skills required across work and university:

Self-reflection for example. In classroom/assignments you reflect on how you could have done it differently or better, at workplace you reflect on how you communicate with others, react in difficult situations. It's the ability to constructively criticise yourself.

Self-reflection needed in both. Good to reflect on what you have done well/ not so well in previous academic/ professional work to know where to improve.

Team working and coming to a conclusion together, discussing different ideas.

Analytical skills to find solutions to problems; resilience and perseverance; adaptability.

Since the data were collected while COVID-19 had changed a lot of the working and studying practices of students (while their employer and degree programme did not change, they were now working from home and studying online), participants also noted the increased importance of some of these skills and their changing nature as they navigated the new situation:

Covid has resulted in me being way more reflective than I would normally expect to be, it is obviously something I have really needed to do to understand what is happening and the impacts.

Teamwork and communication have become more vital working remotely to manage the change of working environment, support each other yet not let work output be affected.

Clear and coherent communication is even more important in a remote working world. As-is active listening.

Additionally, participants discussed what personal attributes might be needed to show this support:

Being authentic and honest is vital - I think I now view these two attributes as being the most important given the last 6 months

Learning agility is a skill needed in this age of rapid innovation and digitisation. It is important for people to be able to learn, grow to keep up with things.

The skills which students pointed to overlapped and interestingly, based on recent events pointed to more reflection and acquiring communication skills needed in online settings. On top of this digital turn, being agile might be a more important skill they need since the changing labour market after COVID-19 will require reallocation in people's roles (Costa Dias et al., 2020). The findings here point to the potential of PBL to get students reflecting on these skills and being able to articulate their importance. 
Is there an obvious convergence between classroom and workplace skills?

When asked about their perceptions of the skills required across the two spheres, students were able to see some overlaps and identify some transferrable skills. Yet one of the frequent questions students asked us is whether their assessments should discuss how they develop skills in the classroom/completing assignments or at the workplace. We have found, term after term, when teaching these modules that students try to create a distinction between what happens at the workplace and what happens in their studies. This disconnect is potentially an issue which results from the general perception that the two are, and should be kept, separate as manifested in the skills gap discussed above. However, through these SML problem-based modules, we try to get students to think how they can develop skills concurrently and if there are any overlaps. When asked to reflect on this, our participants readily noted that they are. For example:

Skills are transferable, however sometimes approached in different ways in the workplace compared to in the classroom.

The participants were asked to give examples of how the skills might be developed at the two settings and what overlaps they identified.

Solving problems and the skills required to do so, regardless of the issue.

Need to work well within your team \& share workloads/ support each other. Peer feedback and group exercises to support everyone's learning.

Emphasis on needing to support others.

Using active listening when obtaining feedback from lecturers, and developing and applying this when talking to SLT (senior leadership team).

We found that students view being supportive of each other as especially important. Perhaps this was reflective of the community spirit displayed during COVID-19. The fact that most of our students had to work from home and had to study online meant that teamwork and sharing tasks became even more important to them. Perhaps the fact that teams only came together virtually, with chance interactions taken away, consolidated the importance of these random interactions.

Overall, we see that when asked to think about the overlaps, there are many. It is encouraging to see that students can see the convergence between the two. From the examples above, we also note that they primarily identify skills which are not formally learnt or often assessed, but they have to do with everyday tasks and being able to get things done or be part of a team.

\section{Workplace/classroom: overlapping sites of learning}

The last component of our research was to identify how students develop these skills in action and how they draw from their classroom and professional experiences. Through these authentic instances of skills development, we see the potential of bridging the two learning sites while creating models for crossovers of skills. The below examples are instances of learning which happens both formally but also through moments of interaction with others and while figuring things out. As we have noted above, we believe that these "lightbulb" moments which prompt students to reflect on their experiences and see what they can take away from them, is when deep learning can take place.

Participant $A$. The below example comes from a student who utilised one of the reflective activities we recommend: keeping a learning journal. The student showed what they did in the previous year (L5) as an example of how they have adopted a structured reflective approach as outlined below:
Self-managed and workbased learning 
JWAM

13,1

Situation: In the seminar today we discussed the application section of the SML report, during which evaluation of the potential solutions would be carried out. [The tutor] discussed a 6-step framework, however, I didn't understand how my action research approach would fit into this. [...]

Analysis of feeling and knowledge: It seemed like a lot of steps for the evaluation and I was worried that I wouldn't be able to communicate all my reasoning and critical thinking [...] I was also conscious that in this section I would need to demonstrate my problem solving.

Evaluation: I think the problem was caused by my premature decision to use an action research approach before properly considering the requirements [...]

Skills developed: communication; problem solving; critical thinking

Changes for future work: clarify questions regarding assessment brief in advance; do not start writing until you are sure on the approach - this wastes time; before detailing an evaluation approach, consider the solution and time frame available

Looking at the processes which students utilise to make sense of what happens in the classroom, especially an online classroom, is invaluable in understanding how these skills can be developed in practice. The student now only identifies what challenges they were faced with but also how they could draw upon their skills to overcome similar challenges in the future. Moreover, some of the learnings here, i.e. considering distinct options before deciding how to solve the problem or clarify questions with those who have set a task are valuable lessons which can be applied to the workplace and are particularly useful for DAs who regularly have to make these decisions as part of their jobs

Participant B. This example is also a reflection of how a student has approached the skills development section in second year undergraduate (L5) and thinking how they can build on this during L6, their current level. The example draws on the workplace and how the student navigated interactions with colleagues while trying to complete their SML project. The student reflects on how they managed to get feedback on their project from colleagues (stakeholders) and how they navigated the process. The student begins by saying how they have looked at what the literature suggested about stakeholder engagement, essentially engaging colleagues with your ideas.

proactively engaging with colleagues and embedding their feedback into the solution. Developing these collaborative relationships enabled expectations to be managed [ . . . whilst also ensuring that colleagues were able to appreciate the value the solution could have for them and their teams. [...] On a personal level, it is hoped that this experience can be used as a platform from which the skills developed, and relationships established can be further developed.

It is encouraging to see that the student successfully bridges the gap between the theory learnt through academic work and the workplace by engaging colleagues and later on implementing solutions successfully. As shown in the excerpt above, practical applications of what the theory might have to say about the workplace and managing relationships can help build relationships in the workplace, something very pertinent to apprentices who have to embed themselves to the workplace.

Both examples outline above show the potential of PBL to help students see the overlaps between the classroom and the workplace while gaining the necessary skills to navigate the two spheres.

\section{Discussion and conclusion}

The persistence of the skills gap manifested in the labour skills shortages as discussed by employers is widely covered. In this paper, we have analysed the case study of a selfmanaged module which takes a problem-based approach to encourage students to reflect 
on the crossovers between the learning which takes place in the classroom and the workplace. By getting students to reflect on the skills they develop while trying to solve a work-based problem, we have found that our participants have been able to identify such overlaps. They often problematised how the two sites of learning link and whether there are crossovers between the two. We discussed how often, as tutors, we are asked whether the reflection on skills development should be kept separate. However, our findings show that there is real potential for students to see the crossings between these two spheres and see how the theory and skills acquired in the classroom can benefit them in their workplace. Since we collected data during the COVID-19 pandemic, we saw a renewed need for teamwork, self-reflection and communication to succeed professionally and academically. However, our participants also pointed to the need to be agile, since circumstances are unforeseen and often required fast thinking and adaptability, which resonates with the work of Costa Dias et al. (2020)

We have provided examples of how the two sites have been bridged and have argued that problem-based, experiential learning embedded in work-based modules has real potential to get students to bridge the gaps between the workplace and the classroom. As the literature and the findings suggest this can be especially relevant to DAs, who work and study at the intersections of professional and academic settings. However, this approach can be applied in other WBL contexts, such as industrial placements or sandwich year programmes. We recognise that since this only one case study in the UK, working with an academically homogenous cohort of DAs, it might not be possible to replicate our findings in other, perhaps international, settings. However, we believe we have pointed to the potential of how this can be done through our model of reflecting on skills. We believe there is scope for further research in the area, looking into other case studies and especially in understanding of the underexplored area of the learning which takes place in the workplace.

\section{References}

Ahmed, S. and Asraf, R.M. (2018), "The workshop as a qualitative research approach: lessons learnt from a 'critical thinking through writing' workshop", The Turkish Online Journal of Design, Art and Communication, Special edition, pp. 1504-1510, ISSN: 2146-5193.

Andrews, J. and Higson, H. (2008), "Graduate employability, 'soft skills' versus 'hard' business knowledge: a European study", Higher Education in Europe, Vol. 33 No. 4, pp. 411-422, doi: 10. 1080/03797720802522627.

Bates, L. and Sampford, K. (2005), Building a Bridge Between University and Employment: WorkIntegrated Learning Queensland Parliamentary Library Research Publications and Resources Section, available at: http://www.parliament.qld.gov.au/Parlib/Publications/publications.htm (accessed 30 October 2020).

Bates, L., Hayes, H., Walker, S. and Marchesi, K. (2018), "From employability to employment: a professional skills development course in a three-year bachelor program", International Journal of Work-Integrated Learning, Vol. 19 No. 1, pp. 413-423.

Billett, S. (1996), "Constructing vocational knowledge: history, communities and ontogeny", Journal of Vocational Education and Training, Vol. 48 No. 2, pp. 141-154.

Billett, S. (2001), "Learning throughout working life: interdependencies at work", Studies in Continuing Education, Vol. 23 No. 1, pp. 19-35, doi: 10.1080/01580370120043222.

Boud, D. and Garrick, J. (Eds) (1999), Understanding Learning at Work, Routledge, London.

Boud, D., Ajjawi, R. and Tai, J. (2020), "Assessing work-integrated learning programs: a guide to effective assessment design", Centre for Research in Assessment and Digital Learning, Deakin University, Melbourne, doi: 10.6084/m9.figshare.12580736 (accessed 30 October 2020). 
JWAM

13,1

Bound, H., Chia, A. and Chee, L.W. (2018), "Spaces and spaces 'in between' - relations through pedagogical tools and learning", in Choy, S., Wärvik, G.-B. and Lindbery, V. (Eds), Integration of Vocational Education and Training Experiences, Springer, Singapore, pp. 243-258.

Bravenboer, D. (2018), "The unexpected benefits of reflection: a case study in university-business collaboration", Journal of Work-Applied Management, Vol. 10 No. 1, pp. 50-62, doi: 10.1108/ jwam-01-2017-0002.

Bravenboer, D. and Lester, S. (2016), "Towards an integrated approach to the recognition of professional competence and academic learning”, Education and Training, Vol. 58 No. 4, pp. 409-421, doi: 10.1108/ET-10-2015-0091.

Bridgstock, R. (2009), “The graduate attributes we've overlooked: enhancing graduate employability through career management skills", Higher Education Research and Development, Vol. 28 No. 1, pp. 31-44, doi: 10.1080/07294360802444347.

Carvalho, A. (2016), "The impact of PBL on transferable skills development in management education”, Innovations in Education and Teaching International, Vol. 53 No. 1, pp. 35-47, doi: 10.1080/14703297.2015.1020327.

CBI and Pearson (2018), Educating for The Modern World: Cbi/Pearson Education and Skills Annual Report, available at: https://www.cbi.org.uk/media/1171/cbi-educating-for-the-modern-world.pdf (accessed 31 October 2020).

Choy, S. (2018), "Integration of learning in educational institutions and workplaces: an Australian case study", Integration of Vocational Education and Training Experiences, Springer, pp. 85-106, doi: 10.1007/978-981-10-8857-5_5.

Costa Dias, M., Joyce, R., Postel-Vinay, F. and Xu, X. (2020), "The challenges for labour market policy during the COVID-19 pandemic", Fiscal Studies, Vol. 41, pp. 371-382, doi: 10.1111/1475-5890.12233.

Crisp, P.M. (2018), "Coaching placements and incidental learning - how reflection and experiential learning can help bridge the industry skills gap", Journal of Learning Development in Higher Education, Plymouth, No. 13, available at: https://journal.aldinhe.ac.uk/index.php/jldhe/article/ view/442 (accessed 2 February 2021).

Cunliffe, A.L. (2002), "Reflexive dialogical practice in management learning", Management Learning, Vol. 33 No. 1, pp. 35-61, doi: 10.1177/1350507602331002.

Dahlgren, M.A. (2000), "Portraits of PBL: course objectives and students' study strategies in computer engineering, psychology and physiotherapy", Instructional Science, Vol. 28, pp. 309-329, doi: 10.1023/A:1003961222303.

Department for Business, Innovation \& Skills and Prime Minister's Office (2015), Press Release: Government Rolls-Out Flagship Degree Apprenticeships, available at: https://www.gov.uk/government/news/ government-rolls-out-flagship-degree-apprenticeships (accessed 11 December 2020).

Department for Business, Innovation \& Skills (2016), Success as a Knowledge Economy: Teaching Excellence, Social Mobility \& Student Choice, (White Paper) available at: https://assets. publishing.service.gov.uk/government/uploads/system/uploads/attachment_data/file/523546/ bis-16-265-success-as-a-knowledge-economy-web.pdf (accessed 19 October 2020).

Fajaryati, N. and Akhyar, M. (2020), "The employability skills needed to face the demands of work in the future: systematic literature reviews", Open Engineering, Vol. 10 No. 1, pp. 595-603, doi: 10. 1515/eng-2020-0072.

Fuller, A., Hodkinson, H., Hodkinson, P. and Unwin, L. (2005), "Learning as peripheral participation in communities of practice: a reassessment of key concepts in workplace learning on JSTOR", British Educational Research Journal, Vol. 31 No. 1, pp. 49-68.

Graham, L., Williams, L. and Chisoro, C. (2019), "Barriers to the labour market for unemployed graduates in South Africa”, Journal of Education and Work, Vol. 32 No. 4, pp. 360-376, doi: 10. 1080/13639080.2019.1620924.

Heaviside, H.J., Manley, A.J. and Hudson, J. (2018), "Higher Education Pedagogies Bridging the gap between education and employment: a case study of problem-based learning implementation in 
postgraduate sport and exercise psychology", Higher Education Pedagogies, Vol. 3 No. 1, pp. 463-477, doi: 10.1080/23752696.2018.1462095.

Hodge, K. and Lear, J. (2011), "Employment skills for 21st century workplace: the gap between faculty and student perceptions", Journal of Career and Technical Education, Vol. 26 No. 2, pp. 28-41.

Jackson, D. and Wilton, N. (2016), "Developing career management competencies among undergraduates and the role of work-integrated learning", Teachinng in Higher Education, Vol. 21 No. 3, pp. 266-286.

Joshua, S., Biao, I., Azuh, D. and Olanrewaju, F. (2015), "Multi-faceted training and employment approaches as panacea to higher education graduate unemployment in Nigeria", Contemporary Journal of African Studies, Vol. 3 No. 1, pp. 1-15.

Knowles, M. (1970), The Modern Practice of Adult Education: Andragogy vs Pedagogy, Associated Press, New York, NY.

Le Clus, M.A. (2011), "Informal learning in the workplace: a review of the literature", Australian Journal of Adult Learning, Vol. 51 No. 2, pp. 355-373.

Livanos, I. (2010), "The relationship between higher education and labour market in Greece: the weakest link?”, Higher Education, Vol. 60 No. 5, pp. 473-489, doi: 10.1007/s10734-010-9310-1.

Mccowan, T. (2015), "Should universities promote employability?", Theory and Research in Education, Vol. 13 No. 3, pp. 267-285, doi: 10.1177/1477878515598060.

Mok, K.H. (2016), "Massification of higher education, graduate employment and social mobility in the greater China region", British Journal of Sociology of Education, Vol. 37 No. 1, pp. 51-71.

Moore, T. and Morton, J. (2017), "The myth of job readiness? Written communication, employability, and the 'skills gap' in higher education", Studies in Higher Education, Vol. 42 No. 3, pp. 591-609, doi: 10.1080/03075079.2015.1067602.

Nicolini, D. (2011), "Practice as the site of knowing: insights from the field of telemedicine", Organization Science, Vol. 22 No. 3, pp. 602-620, doi: 10.1287/orsc.1100.0556.

O'Connor, H., Madge, C., Shaw, R. and Wellens, J. (2008), "Internet-based interviewing", in Fielding, N.G., Lee, R.M. and Blank, G. (Eds), The Sage Handbook of Online Research Methods, Sage, London.

Ochieng, N.T., Wilson, K., Derrick, C.J. and Mukherjee, N. (2018), “The use of focus group discussion methodology: insights from two decades of application in conservation", Methods in Ecology and Evolution, Vol. 9, pp. 20-32, doi: 10.1111/2041-210X.12860.

Ørngreen, R. and Levinsen, K. (2017), "Workshops as a research methodology”, The Electronic Journal of e-Learning, Vol. 15 No. 1, pp. 70-81, available at: www.ejel.org (accessed 29 October 2020).

Ramsey, C. (2011), "Provocative theory and a scholarship of practice", Management Learning, Vol. 42 No. 5, doi: 10.1177/1350507610394410.

Ramsey, C. (2014), "Management learning: a scholarship of practice centred on attention? Journal Item”, Management Learning, Vol. 45 No. 1, pp. 6-20, doi: 10.1177/1350507612473563.

Scholtz, D. (2020), “Assessing workplace-based learning”, International Journal of Work-Integrated Learning, Vol. 21 No. 1, pp. 25-35.

Smith, K., Clegg, S., Lawrence, E. and Todd, M.J. (2007), "The challenges of reflection: students learning from work placements", Innovations in Education and Teaching International, Vol. 44 No. 2, pp. 131-141, doi: 10.1080/14703290701241042.

Smith, M., Duncan, M. and Cook, K. (2013), "Graduate employability: student perceptions of PBL and its effectiveness in facilitating their employability skills", Practice and Evidence of Scholarship of Teaching and Learning in Higher Education, Vol. 8 No. 3, pp. 217-240.

Succi, C. and Canovi, M. (2020), "Soft skills to enhance graduate employability: comparing students and employers' perceptions", Studies in Higher Education, Vol. 45 No. 9, pp. 1834-1847, doi: 10. 1080/03075079.2019.1585420. 
JWAM

13,1

18
Svensson, L. and Randle, H. (2005), "How to 'Bridge the Gap' - Experiences in connecting the educational and work system", in Antonacopoulou, E., Jarvis, P., Andersen, V., Elkjaer, B. and Høyrup, S. (Eds), Learning, Working and Living, Palgrave Macmillan, London, doi: 10.1057/ 9780230522350_7.

Tymon, A. (2013), "The student perspective on employability", Studies in Higher Education, Vol. 38 No. 6, pp. 841-856, doi: 10.1080/03075079.2011.604408.

Wall, T. (2016), "Žižekian ideas in critical reflection the tricks and traps of mobilising radical management insight”, Journal of Work-Applied Management, Vol. 8 No. 1, pp. 5-16, doi: 10.1108/ JWAM-04-2016-0005.

Wellman, N. (2010), "The employability attributes required of new marketing graduates", Marketing Intelligence and Planning, Vol. 28 No. 7, pp. 908-930, doi: 10.1108/02634501011086490.

Young, M.R. (2018), "Reflection fosters deep learning: the 'reflection page and relevant to you' intervention”, Journal of Instructional Pedagogies, Vol. 20, pp. 1-17.

\section{Further reading}

Browne, J. (2010), Securing a Sustainable Future for Higher Education: An Independent Review of Higher Education Funding and Student Finance, Department for Business, Innovation and Skills, October. available at: https://www.gov.uk/government/publications/the-browne-reporthigher-education-funding-and-student-finance (accessed 31 October 2020).

\section{Corresponding author}

Iro Konstantinou can be contacted at: iro.konstantinou@pearsoncollege.com

For instructions on how to order reprints of this article, please visit our website: 